[Technical Paper]

\title{
High Heat Proofing Nano-Layered Film Cu Wiring Using Crystal Grain Growth Control
}

\author{
Haruhiko Miyagawa, Ryohei Satoh, Yoshiharu Iwata, Eiji Morinaga, and Kouji Nakagawa \\ Osaka University, Yamadaoka 2-1, Suita-shi, Osaka 565-0871 Japan
}

(Received July 27, 2010; accepted October 11, 2010)

\begin{abstract}
$\mathrm{Cu}$ is gaining a lot of attention as the main wiring material for next generation devices. However, $\mathrm{Cu}$ oxidizes in hightemperature heat treatments. For heat-proofing considerations, a $\mathrm{Cr} / \mathrm{Cu} / \mathrm{Cr}$ system is widely used. Currently, the required $\mathrm{Cr}$ layer is too thick and $\mathrm{Cr}$ is environmentally problematic. Therefore, we focused on the stable oxide, $\mathrm{SnO}_{2}$, and were able to increase heat proofing by covering $\mathrm{Cr} / \mathrm{Cu} / \mathrm{Cr}$ with $\mathrm{SnO}_{2}$. This was able to tolerate a heat treatment of $873 \mathrm{~K}$ for $1800 \mathrm{~s}$ in air. $873 \mathrm{~K}$ is the highest temperature in the PDP manufacturing process, which has an especially severe heat treatment for various devices. However, some oxidization along the grain boundary was observed. In order to further increase reliability, we then investigated the elucidation of an oxidation mechanism. We show clearly that $\mathrm{Cu}$ crystal grain growth is the most important factor for the oxidation. Based on this fact, we tried to control grain growth and improve heat proofing by inserting one or more $\mathrm{Cr}$ layers into the $\mathrm{Cu}$ layer. The result looks like a mille-feuille or Napoleon pastry. As a result, grain growth was controlled and heat proofing greatly improved.
\end{abstract}

Keywords: High Heat Proofing, Oxidation, Multi-layer, $\mathrm{Cu} / \mathrm{Cr} / \mathrm{SnO}_{2}$ Thin Film, Crystal Grain Growth, Insertion Cr Layer

\section{Introduction}

Electronic products such as semiconductors and displays are not realized without progress in digital devices. In such digital devices, $\mathrm{Cu}$ is used widely as a main wiring material of the electronic circuits. However, since the adhesiveness of $\mathrm{Cu}$ with a surface oxide film is weak, in a high-temperature, or oxidizing atmosphere, it cannot be used independently.[1] Thus, in order to secure oxidation resistance with various heat treatments used during the manufacture of devices, protective layers, such as $\mathrm{Cr}$, are used.[2] However, a very thick $\mathrm{Cr}$ film is needed for oxidation resistance. Also $\mathrm{Cr}$ may oxidize at high temperatures to hexavalent chromium, which is harmful to people (This oxidation does not happen under usual heat-treatment conditions). Therefore, it is necessary to reduce the amount of $\mathrm{Cr}$ used as much as possible. So realization of the high heat stability with a thin film of a nano order is desired.

For these reasons, we studied $\mathrm{Cr} / \mathrm{SnO}_{2}$ [3-5] as a protective layer. In this case, $\mathrm{Cr}$ is an adhesive layer. $\mathrm{SnO}_{2}$ is a very stable oxide and can be expected to prevent inflow of oxygen. Moreover, it is useful in PDP[6] (plasma display panel) manufacturing, which uses a high process temperature (1800 s at $873 \mathrm{~K}$ in air), as it is not dissolved in a dielectric.

$\mathrm{Cu}$ crystal grain growth under a high-temperature heat treatment is easily predicted. The diameter of the $\mathrm{Cu}$ crystal grain after heat treatment is calculated by the formula[7, 8]

$$
d^{2}-d_{0}^{2}=K t \cdot \exp \left(-Q_{g b} / R T\right)
$$

where $d_{O}$ is the initial grain size, $t$ is the time, $Q_{\mathrm{gb}}$ is the activation energy for grain boundary diffusion, $T$ is the heat treatment temperature, and $K$ and $R$ are constants. When values of $K=3.59 \mathrm{~m}^{2} / \mathrm{s}$ and $Q=72470 \mathrm{~J} / \mathrm{mol}$ are substituted into the equation, $[9,10] d$ is equal to $3.45 \mu \mathrm{m}$. Considering that the thickness of the wiring is $1 \mu \mathrm{m}$, protective layers will be subjected to stress. In $\mathrm{Cu} / \mathrm{Cr}$, it is thought that this stress is suppressed by the very thick $\mathrm{Cr}$. In this paper, we investigated whether stress from crystal grain growth and oxidization could be suppressed by protective layers of a nano order. 


\section{Experimental}

$\mathrm{Cu}$ multi layers were formed by EB (electron beam) plasma deposition. EB plasma deposition can form a continuous film with high adhesiveness.[11]

The outline of the equipment is shown in Fig. 1. The film-forming conditions are shown in Table $1 . \mathrm{Cr}$ and $\mathrm{Cu}$ of 99.99\% (4Ns) purity were used to form the film.

Ultrasonic washing of the substrate was carried out in pure water and ethanol as a pretreatment of film forming, with $\mathrm{O}_{2}$ washing in a vacuum. The basic film composition is shown in Fig. 2.

In order to simulate an actual manufacturing process, the created sample was held for about $1800 \mathrm{~s}$ after heating to $873 \mathrm{~K}$, which is the softening point of the $\mathrm{Pb}$-free dielectric paste in air. It was then cooled. Observation of the surface state before and after heat treatment was performed using FE-SEM (field emission scanning electron microscopy) and an optical microscope. An SEM cross-sectional observation was conducted after processing with FIB

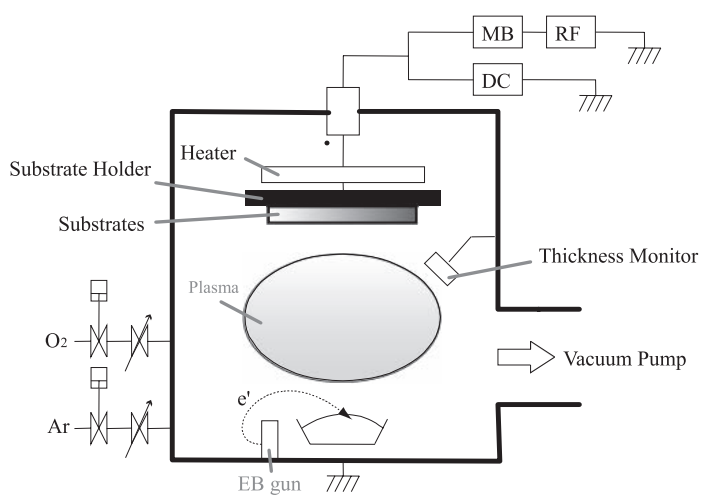

Fig. 1 Schematic diagram of the EB Plasma Deposition apparatus.

Table 1 Condition of thin film formations by EB Plasma.

\begin{tabular}{l|c|c|c|c|c}
\hline \multicolumn{1}{c|}{ Target } & $\mathrm{Cr}_{2} \mathrm{O}_{3}$ & $\mathrm{Cr}(4 \mathrm{~N})$ & $\mathrm{Cu}(4 \mathrm{~N})$ & $\mathrm{Cr}(4 \mathrm{~N})$ & $\mathrm{SnO}_{2}$ \\
\hline Deposition rate $(\mathrm{nm} / \mathrm{s})$ & 0.1 & 0.5 & 0.7 & 0.5 & 0.2 \\
\hline Substrate heating & \multicolumn{5}{c}{ No heating } \\
\hline RF power (W) & \multicolumn{5}{c}{500} \\
\hline
\end{tabular}

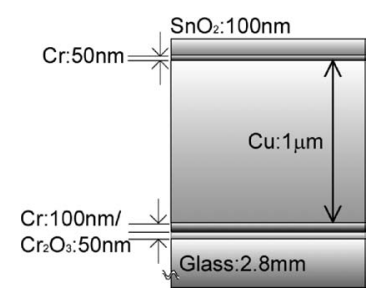

Fig. 2 Structure of $\mathrm{Cu} / \mathrm{Cr} / \mathrm{SnO}_{2}$ multi-layered film. (focused ion beam). W (tungsten) was deposited to protect the surface coat at the time of cross-sectional processing. Crystal orientation analysis was performed using EBSP (electronic backscattering diffraction pattern). Surface form and unevenness were measured and analyzed using an AFM (atomic force microscope).

\section{Results and Discussion}

\subsection{Heat-resistance degradation mechanism}

In spite of being covered by $\mathrm{SnO}_{2}$ which is a stable oxide, the $\mathrm{Cu}$ thin film was oxidized after heat treatment. At this time, the $\mathrm{Cu}$ crystal grains were growing rapidly. Accordingly, from various examination results, the heat resistance degradation mechanism in $\mathrm{Cu} / \mathrm{Cr} / \mathrm{SnO}_{2}$ system was inferred. The details are given below using the mimetic diagram of Fig. 3 .

(1) As-deposited $\mathrm{Cu}$ formed a detailed crystal structure of about $20 \mathrm{~nm}$ scale (Fig. 3(a)).

(2) When this sample was subjected to a high-temperature heat treatment of $823 \mathrm{~K}$, the surface remained flat and smooth, and the $\mathrm{Cu}$ crystal grains were still detailed during the time of the SEM observation. However, a stacking fault with a direction equal to the vertical section observation is seen with the SEM. Similarly, the horizontal crystal orientation analysis using EBSP shows grain growth of the internal $\mathrm{Cu}$ on the order of several microns (Fig. 3(b)). At this time, we see from the SEM image that the vertical grain growth of the $\mathrm{Cu}$ is suppressed and growing only horizontally. However, crystal grains tend to grow to a globular form, which is stable in energy. Here, since the surface protection layer prevents that, we considered that a high degree of strain occurs at the interface with the protection layer near the newly formed $\mathrm{Cu}$ grain boundary. Because of the strain, a diffusion path which is not observed by SEM is formed in the protection layer along the $\mathrm{Cu}$ crystal grains.

(3) Oxygen flowing through the diffusion path causes a cubical expansion $\left(\mathrm{V}_{\mathrm{Cr}_{2} \mathrm{O}_{3}} / V_{\mathrm{Cr}}=1.97\right)$ by the oxidation of $\mathrm{Cr}$. Moreover, when oxygen diffuses through the $\mathrm{Cu}$ grain boundary and is supplied to a lower layer $\mathrm{Cr}$, a part of the $\mathrm{Cu}$ grain boundary oxidizes. Furthermore, $\mathrm{Cu}$ crystal grain growth is also accelerated with higher heat-treatment temperatures. More stress is put on the protective layer by this oxidation, expansion, and $\mathrm{Cu}$ crystal 


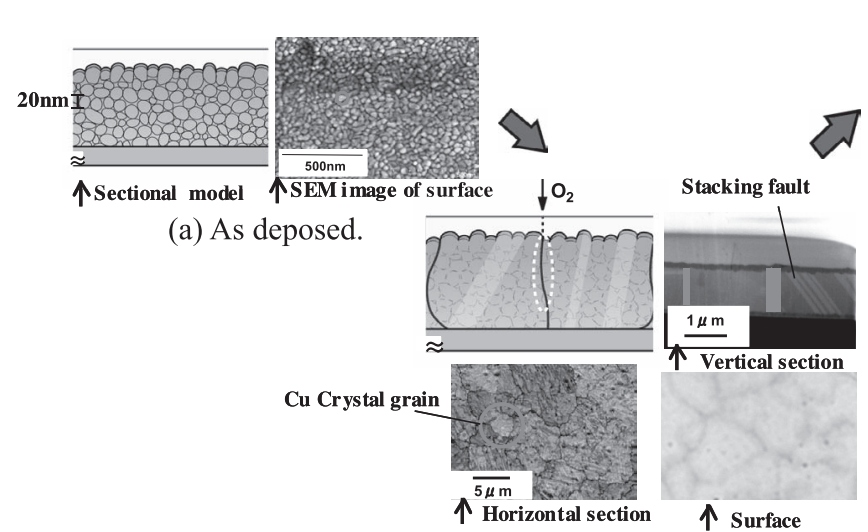

(b) Annealed at $823 \mathrm{~K}$ of $1800 \mathrm{~s}$.

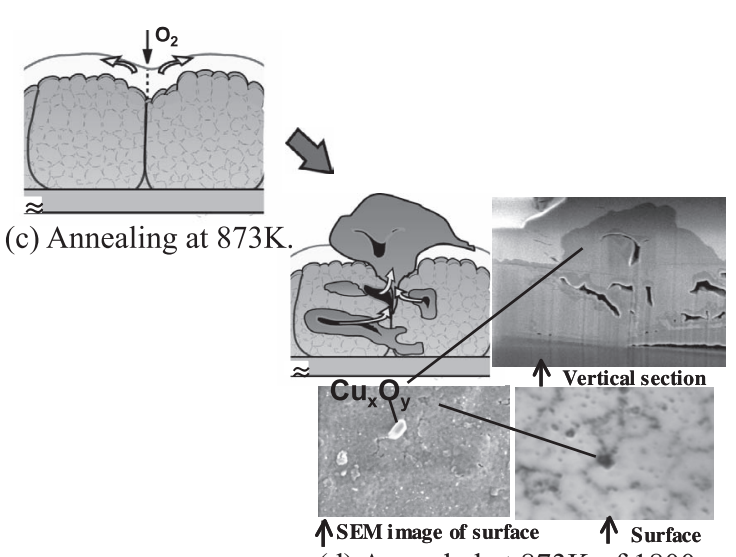

(d) Annealed at $873 \mathrm{~K}$ of $1800 \mathrm{~s}$.

Fig. 3 Schematic diagram of the oxidation mechanism.

grain growth advance. The protective layer changes shape under this stress causing the unevenness which follows the $\mathrm{Cu}$ crystal grain. Thus, the diffusion path is extended and will evolve into a visible micro crack (Fig. 3(c)).

(4) Because the diffusion path extends to micro cracks, $\mathrm{Cu}$ atoms can easily diffuse to the surface. $\mathrm{Cu}$ diffused to the surface oxidizes and black point (Oxide) is formed (Fig. 3(d)). The wiring changes shape significantly due to the diffusion of internal $\mathrm{Cu}$ to the surface. The protective layer cannot maintain the original form. Oxidization advances at an accelerated pace because of the loss of the protective function of the $\mathrm{SnO}_{2}$ film. At worst, disconnection can result.

Thus, we presumed that the predominant factor of $\mathrm{Cu}$ oxidization in a $\mathrm{Cu} / \mathrm{Cr} / \mathrm{SnO}_{2}$ system thin film wiring was Cu's own crystal grain growth. That is, if the crystal grain growth of $\mathrm{Cu}$ can be controlled, heat-resistance degradation may be prevented by the thin $\mathrm{SnO}_{2}$. Next, by controlling the growth of the $\mathrm{Cu}$ crystal grain, we verified a presumed rule factor and investigated how to raise the heat resistance.

\subsection{Controlling $\mathrm{Cu}$ crystal grain growth}

To control $\mathrm{Cu}$ crystal grain growth, we investigated lamination wiring with $\mathrm{Cr}$ layers inserted into the $\mathrm{Cu}$ layer, as shown in Fig. 4. From this structure, we expected to mitigate stress on the protective layer by controlling crystal grain growth, maintaining low resistance. Fig. 5 shows the SEM verticality section image of these samples after heat treatment. This result shows that $\mathrm{Cr}$ clearly exists in layers after the heat treatment and the laminated structure is maintained.

Next, we investigated the heat-resistance effect of a lam-

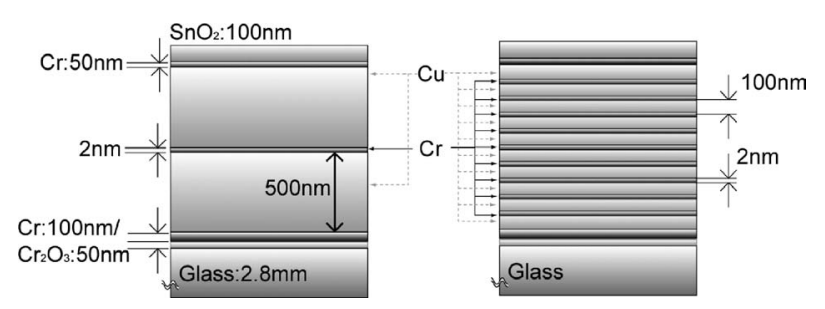

Fig. 4 Structure of $\mathrm{Cu}$ multi-layered film which $\mathrm{Cr}$ inserted.

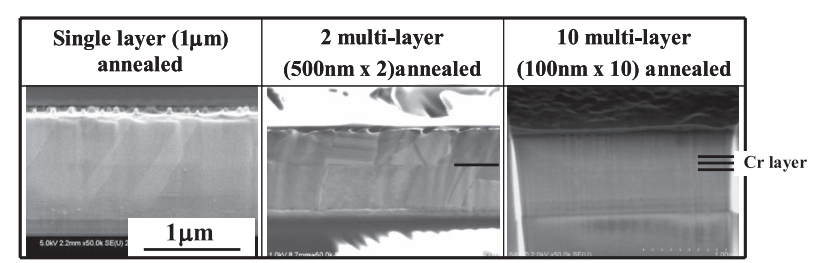

Fig. 5 The cross section of $\mathrm{Cu} / \mathrm{Cr}$ multi-layer after heat treatment.

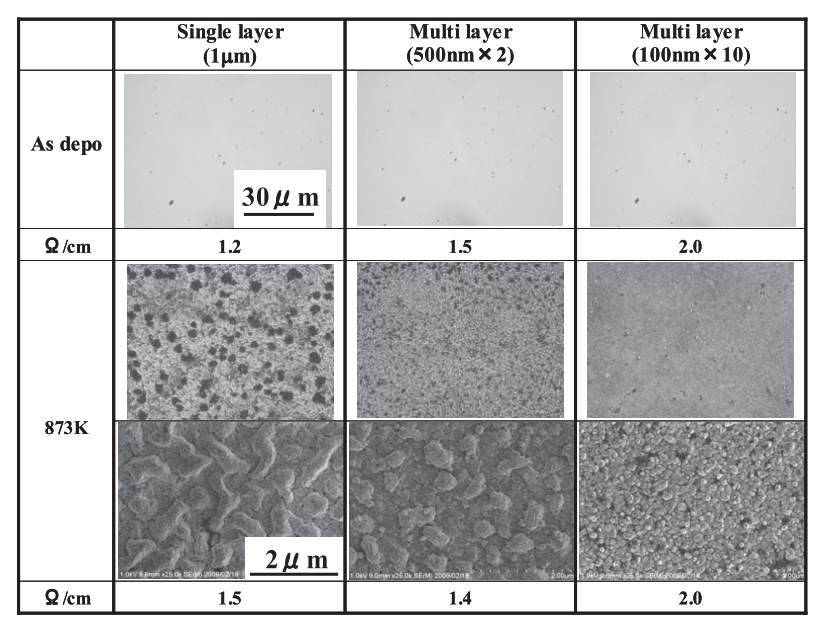

Fig. 6 The surface oxidation and asperity observation before and after heat treatment.

inated structure. Observations of the surface changes of a single layer ( $=1 \mu \mathrm{m}$ for $\mathrm{Cu}$ layers) and laminated layers are shown in Fig. 6, and the measurement result of surface 


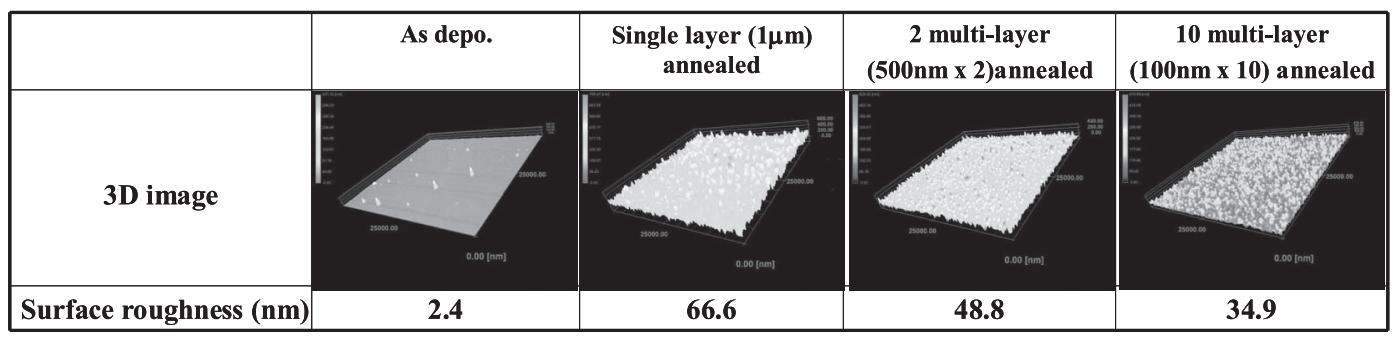

Fig. 7 Surface average roughness after heat treatment under each thin film circuit structure.

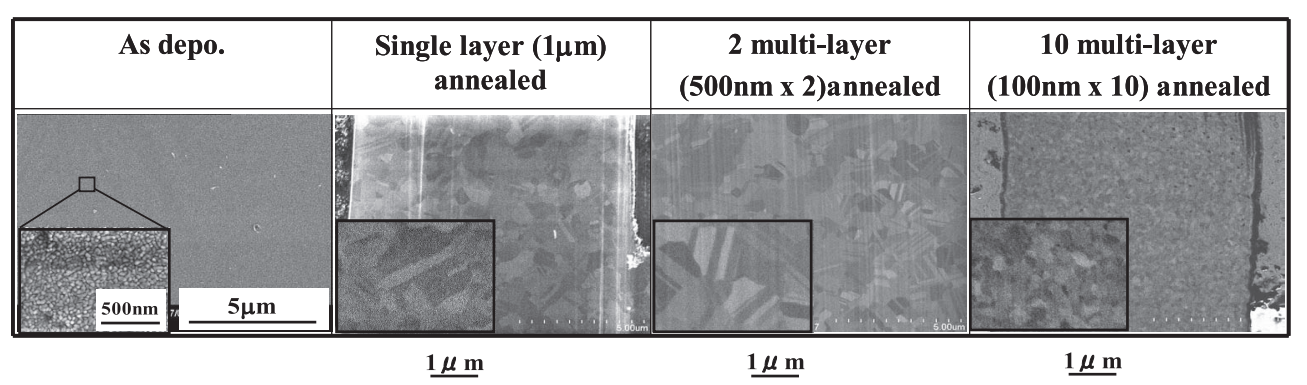

Fig. 8 The observation of control effect of $\mathrm{Cu}$ horizontal crystal grain growth by multi layered.

coarseness is shown in Fig. 7. From these results, it can be seen that the surface of the single layer wiring oxidized and the black point (Oxide) was increased after the heat treatment. On the other hand, in lamination wiring, generation of a surface oxide is suppressed as the number of divisions increases. Moreover, the irregularity of the surface, which is probably based on $\mathrm{Cu}$ crystal grain growth, was also suppressed. We consider that these results were clearly due to the influence of the inserted Cr layers.

Next, we investigated the influence of the inserted $\mathrm{Cr}$ layers on the $\mathrm{Cu}$ crystal grain growth suppression. Each sample was processed using FIB and the comparison of the substrate $\mathrm{Cu}$ crystal grain size in the horizontal direction after heat treatment is shown in Fig. 8. From this result, it can be seen that the approximately $20 \mathrm{~nm}$ initial particle diameter has grown to the order of $1-2 \mu \mathrm{m}$ after heat treatment in the single layer. On the other hand, in the ten division layers, growth could then be controlled to about 100-200 nm, and grain growth could be held down to about $500-800 \mathrm{~nm}$ in the 2 division layers. The Cr layer inserted into the layers played the role of a growth suppression factor for $\mathrm{Cu}$ crystal grains.

The average particle diameter after heat treatment and its relation to the film thickness of the $\mathrm{Cu}$ layer are shown in Fig. 9. This result also shows that particle diameter is dependent on film thickness. We also clarified that crystal grain size can be controlled by varying the number of layers in the $\mathrm{Cu}$ lamination structure. These results show the possibility of realizing highly heat-resistant $\mathrm{Cu}$-system

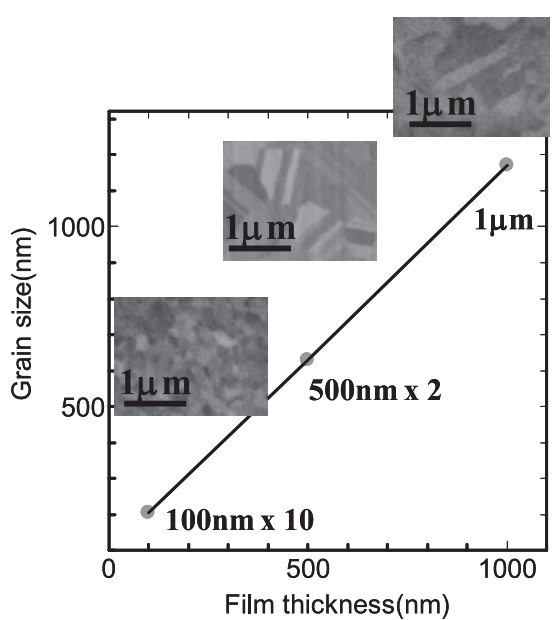

Fig. 9 The relationship between film thickness and grain size after heat treatment.

thin-film wiring by controlling the $\mathrm{Cu}$ crystal grain growth. One proof that the factor which degrades the heat resistance of $\mathrm{Cu} / \mathrm{Cr} / \mathrm{SnO}_{2}$ system wiring is growth of $\mathrm{Cu}$ crystal grain could be shown.

However, in the laminated structure which we investigated here, not only the direction of film thickness but horizontal crystal grain growth was controlled. Thus, we are concerned about an increase in specific resistance. In the future, we plan to investigate the proper film thickness of the $\mathrm{Cu}$ and $\mathrm{Cr}$ layer in consideration of the trade-off between heat proofing and resistance, as well as the proper number of $\mathrm{Cr}$ layers, etc., in a laminated structure. 


\section{Conclusion}

This paper investigated the oxidization and crystal grain growth of $\mathrm{Cu}$ in $\mathrm{Cu} / \mathrm{Cr} / \mathrm{SnO}_{2}$ system multi-layers. We conclude that

1. The grain growth of $\mathrm{Cu}$ is the dominant factor affecting $\mathrm{Cu}$ oxidization in $\mathrm{Cu} / \mathrm{Cr} / \mathrm{SnO}_{2}$.

2. Control of grain growth is possible by inserting Cr layers into the $\mathrm{Cu}$ layer, and grain size is dependent on the $\mathrm{Cu}$ film thickness. By controlling the grain growth, heat resistance was greatly improved.

\section{References}

[1] C.-K. Hu, D. Gupta, I. T. Wetzel, and P. S. Ho, "Thin Films-Interfaces and Phenomena,” Mat. Res. Soc., p. 153, 1986.

[2] J. Schumann, W. Bruckner, and A. Heinrich, "Properties and applications of vacuum deposited $\mathrm{Cu}-\mathrm{Cr}$ films," Thin Solid Film, Vol. 228, p48, 1993.

[3] T. Isono, T. Fukuda, K. Nakagawa, R. Usui, R. Satoh, E. Morinaga, and Y. Mihara, "Highly conductive $\mathrm{SnO}_{2}$ thin films for flat-panel displays," Proc. SID, pp. 161-166, 2007.

[4] Y. Mihara, R. Satoh, R. Usui, E. Morinaga, and Y.
Iwata, “Ta-Doped SnO2 Thin Films for PDP,” Proc. SID, pp. 399-402, 2007.

[5] R. Usui, "Research on Direct Laser Patterning of Thin Films for Flat-Panel Display," Proceedings of the $24^{\text {th }}$ International Congress on Applications of Lasers \& Electro-Optics, pp. 13-19, 2005.

[6] M. Kawamura, "Yokuwakaru Plasma Display Panels," Denpashinbunsya, 2002 (in Japanese).

[7] Y. Koda, "Kinzoku Butsurigaku Joron," CORONA PUBLISHING CO., 1964.

[8] Japan Institute of Metals, "Teniron - Sono Kinzokugaku He No Ouyou -," Maruzen CO., 1971.

[9] S. Fujikawa, "Self-Diffusion in Copper Single Crystal,” JRIC, Vol. 42, pp. 331-335, 2003.

[10] J. Lian, R. Z. Valiev, and B. Baudelet, "On the Enhanced Grain Growth in Ultrafine Grained Metals," Acta Metall. Mater, Vol. 43, pp. 4165-4170, 1995.

[11] K. Uetani, H. Kajiyama, T. Yamaguchi, K. Nose, K. Onisawa, and T. Minemura, "Ultra Thin Films Prepared by an Advanced Ion-Plating Method," Materials Transactions, Japan Institute of Metals, pp. 1161-1163, 2000. 